\title{
Intrauterine condom catheter tamponade in the management of atonic postpartum haemorrhage: a case series from a tertiary care centre in Central India
}

\author{
Moushmi B. Parpillewar*, Shalini S. Fusey
}

Department of Obstetrics and Gynecology, Government Medical College, Nagpur, Maharashtra, India

Received: 24 May 2017

Accepted: 20 June 2017

*Correspondence:

Dr. Moushmi B. Parpillewar,

E-mail: drmoushmi@yahoo.co.in

Copyright: () the author(s), publisher and licensee Medip Academy. This is an open-access article distributed under the terms of the Creative Commons Attribution Non-Commercial License, which permits unrestricted non-commercial use, distribution, and reproduction in any medium, provided the original work is properly cited.

\begin{abstract}
Background: Postpartum haemorrhage (PPH) is the leading cause of maternal mortality worldwide with a prevalence rate of approximately $6 \%$ and 50\% is due to atonic PPH. According to WHO 2014- in India 45,000 maternal deaths take place annually and $20-60 \%$ are due to postpartum hemorrhage. Various medical and surgical methods are available. Uterine balloon tamponade is one of the methods reported increasingly with good success rates avoiding surgical morbidity.

Methods: Prospective data of all women who went into atonic primary PPH after 28 weeks of gestation was collected over a period of one year.

Results: Out of the 252 women who had atonic PPH, 23 were inserted with condom balloon catheter after medical management. Success rate was $18 / 23(78.2 \%)$.

Conclusions: Condom catheter is a non-invasive, effective, conservative method of PPH management. In cases of failure it provides a temporary tamponade effect and time to prepare for other interventions.
\end{abstract}

Keywords: Condom catheter, Maternal death, Postpartum haemorrhage, Tamponade

\section{INTRODUCTION}

Worldwide about half a million women die as results of complications of pregnancy and childbirth. ${ }^{1}$ Nearly all $(99 \%)$ of these deaths are in low and middle income countries. $^{2}$ Haemorrhage, usually occurring in the postpartum period, is responsible for between one quarter and one third of obstetric deaths. ${ }^{3}$

According to the World health organization, obstetrics haemorrhage causes 127,000 deaths annually worldwide and is the leading cause of maternal mortality. ${ }^{4}$ Postpartum haemorrhage (PPH) is the leading cause of maternal mortality worldwide with a prevalence rate of approximately $6 \%$ and $50 \%$ is due to atonic PPH.
In Africa and Asia, PPH accounts for more than $30 \%$ of all maternal deaths. Maternal death due to PPH varies considerably between developed and developing countries, suggesting that deaths from $\mathrm{PPH}$ are preventable. ${ }^{5}$ The United Nations issued 8 Millennium Development Goals (MDG) the fifth goal (MDG-5) stipulated a reduction of the maternal mortality rate to 75 percent by $2015 .^{6}$

India alone accounts for over $20 \%$ of the global maternal deaths even though it has only16\% of world population. ${ }^{7}$ According to WHO 2014- 303,000 maternal deaths occur worldwide each year, out of which in India 45,000 maternal deaths take place. $20-60 \%$ is due to postpartum hemorrhage [One Quarter Deaths WorldwideWHO2014]. ${ }^{8}$ There are 14 million cases of PPH per year. 
Reported incidence of PPH in India is $2 \%-4 \%$ after vaginal delivery and $6 \%$ after caesarean section with uterine atony being the most common cause $(50 \%) .{ }^{9}$ As reported by Registrar, General, India and Centre for Global Health Research 2001-2003; out of the five most common direct causes of pregnancy-related mortality in India first cause was haemorrhage leading to $38 \%$ maternal deaths. ${ }^{10}$ Various medical and surgical methods of management of PPH have been tried and tested. Ultimate and definitive method being, hysterectomy to control bleeding and save mothers life when all other measures fail. Recently various types of uterine balloon tamponade have been reported increasingly with good success rates avoiding surgical morbidity.

The purpose of this study is to evaluate the effectiveness of condom catheter balloon tamponade in atonic PPH management to prevent hysterectomy and to report our experience of its use.

\section{METHODS}

This study was carried out in the department of Obstetrics and Gynecology of Government Medical College, Nagpur which is a tertiary care teaching hospital of central India. It gets referral from all over central India with delivery rare of about 10,000 deliveries per year. After approval from the Institutional Ethics Committee, prospective data of all women who delivered from 1 Jan to 31 Dec 2015 in the department was obtained. Clinical details of all women who went into atonic PPH was collected. Types of management received for atonic PPH in the form of medical, surgical, non-surgical were noted.

\section{Inclusion and exclusion criteria}

All women with atonic PPH who delivered vaginally after 28 weeks of gestation were included. Primary postpartum hemorrhage was defined as the loss of more than $500 \mathrm{ml}$ of blood within the first 24 hours of delivery or loss of any amount that is enough to cause hemodynamic instability in the mother or loss of more than $10 \%$ of the total blood volume. All women with traumatic PPH, PPH due to coagulation defect and women with secondary PPH were excluded. Women who delivered by caesarean were also excluded.

A stepwise approach in the management of PPH was followed according to the hospital protocol.

\section{Step 1 Initial assessment and treatment}

1. Resuscitation

- Large bore

- Oxygen by mask

- Monitor BP, P, R, urine output \pm catheter, \pm oxygen saturation

2. Etiology is assessed

- Explore uterus (tone, tissue)
- $\quad$ Explore (trauma)

- Retained placenta/ POCs

- Review history (thrombin)

3. Laboratory tests

- $\mathrm{CBC}$

- Coagulation screen

- Group and cross match

Steps 2 Directed Therapy

1. Tone

- Massage

- Compress

- Drug

2. Tissue

- Manual removal

- Curettage

3. Trauma

- Correct inversion

- Repair laceration

- Identify rupture

4. Thrombin

- Reverse

- Anticoagulation

- Replace factors

Step 3 Intractable PPH

1. Get Help

- Obstetrician/Surgeon

- Anaesthesiologist

- Lab and ICU

2. Local Control

- Manual compression

- Balloon catheter

- Embolization

3. BP and coagulation

- Crystalloid

- Blood products

Step 4 Surgery

1. Repair

- Lacerations

2. Ligate Vessels

- Uterines

- Ovarian

- Internal iliac artery

- Brace sutures- B-Lynch

3. Hysterectomy 
Women who delivered vaginally and who failed to respond to routine medical methods of management of atonic PPH, intrauterine condom catheter was inserted. Simple things like a condom, a Foley's catheter, a string, an IV set and a bottle of normal saline are required. A Foley's catheter was inserted in a condom and a string was tied at the end of the condom to fix it over the catheter. This assembly was inserted into the uterine cavity and an IV set was attached to the Foley's to which a bottle of normal saline was attached. The condom was inflated with $250-300 \mathrm{ml}$ of normal saline. This inflated balloon catheter was kept for 24-48 hrs. Antibiotics were administered for 24-48 hrs. Clinical success was defined as control of bleeding without further intervention. Mother was followed in postnatal period up to discharge from hospital and any morbidity and mortality noted.

\section{RESULTS}

Total number deliveries in the above period were 11,985 . A total of 538 patients had $\mathrm{PPH}$, the incidence of $\mathrm{PPH}$ being $4.5 \%$. Out of these 252 cases had atonic PPH. Table 1 shows the risk factors for atonic PPH in the 252 cases.

Table 1: The risk factors for atonic postpartum haemorrhage.

\begin{tabular}{|ll|}
\hline Risk factor & Number $\mathbf{n = 2 5 2}$ \\
\hline Multiparity & 81 \\
\hline Antepartum haemorrhage & 56 \\
\hline Anemia & 35 \\
\hline Multiple pregnancy & 26 \\
\hline Prolonged labour & 19 \\
\hline Large for gestational age & 13 \\
\hline Polyhydramnios & 12 \\
\hline Others & 10 \\
\hline
\end{tabular}

Out of the 252 patients of atonic PPH, 142 patients were managed with uterotonics and bleeding was controlled. 76 patients required additional surgical procedures like B-lynch and other brace sutures, systematic devascularisation of uterus. Obstetric hysterectomy was done directly in 10 patients as their condition demanded it. 23 were inserted with condom catheter and 1 patient was sent for uterine artery embolization. Table 2 shows clinical characteristics of patient who underwent condom catheter.

Of the 23 cases, 18 were successful without further intervention. 5 cases had failure, in 4 cases abdomen was opened, devascularisation was carried out and only case responded. In remaining 3 cases hysterectomy had to be done. In 1 case, uterine artery embolization was done as patient was hemodynamically stable and she was not willing for any surgery. Average duration of keeping the balloon in situ was 30 hours 14 minutes.

Twenty-two patients received blood transfusions (range, 1 to 11 units of packed red blood cells with a mean of 3 units per patient). There were no cases of re-bleeding after balloon removal. All patients received higher antibiotics for 24-48 hrs. All patients recovered well without severe morbidity. 2 patients had postpartum fever which responded to routine antibiotics. There was no maternal death in our case series.

Table 2 showing the clinical characteristics of the patients.

\begin{tabular}{|ll|}
\hline Clinical characteristics & Number $\mathbf{n = 2 3}$ \\
\hline Age (years) & \\
\hline $20-25$ & 11 \\
\hline$>25-30$ & 8 \\
\hline$>30-35$ & 2 \\
\hline$>35-40$ & 1 \\
\hline$>45$ & 1 \\
\hline Parity & \\
\hline 1 & 5 \\
\hline $2-3$ & 16 \\
\hline$>3$ & 2 \\
\hline Gestational age at delivery (weeks) & \\
\hline $28-34$ & 3 \\
\hline$>34-40$ & 14 \\
\hline$>40$ & 6 \\
\hline Birth weight in grams & \\
\hline$<2500$ & 1 \\
\hline $2500-3500$ & 14 \\
\hline$>3500$ & 8 \\
\hline
\end{tabular}

\section{DISCUSSION}

Surgical options for major PPH include uterine compression sutures, vessel ligation and hysterectomy. These procedures are lifesaving but are invasive, involve laparotomy, require expertise, may be associated with significant morbidity and may compromise future fertility. Interventional radiology offers a minimally invasive, fertility-preserving alternative but requires special equipment, trained interventional radiologists and may not be readily available in many units. Recently, balloon tamponade has been widely used in the management of PPH unresponsive to standard management. Balloon tamponade is a simple procedure which is readily available in most units and can be easily performed by junior doctors and paramedical staff under supervision and has the advantages of immediate results, low cost and less morbidity. The overall success rate of balloon catheter in present study was $78.2 \%$ which was comparable with other studies. Goldrath first described the use of Foley's catheter tamponade, successful in 17 out 0 f 20 patients $(85 \%) .{ }^{11}$ Various devices have been used for uterine tamponade such as the SengstakenBlakemore tube, Bakri balloon, Rusch balloon, Foley's catheter and the condom catheter balloon. ${ }^{12-14}$ Rusch balloon has the advantages of a larger capacity (a maximum of $1500 \mathrm{~mL}$ ) and low cost. ${ }^{14}$ Bakri balloon has a capacity of $500 \mathrm{~mL}$ and is made of silicon instead of latex. An added advantage is that it has a drainage 
channel to allow blood drainage from the uterine cavity. The only disadvantage being its cost. A review of case reports of balloon tamponade in the management of PPH by Georgiou (2009) showed that success was obtained in 97/106 (91.5\%) cases. $^{15}$ Rathod et al used Foley's catheter for tamponade and reported a success rate of $94 \% .^{16}$

In present study, the balloon was inflated for an average of 30 hours before removal. Studies by Condous GS et al and Seror $\mathrm{J}$ et al. ${ }^{17,18}$ quote similar results and duration of balloon tamponade in their studies was an average of 26 hour 14 minutes and 30 hours respectively. There were 2 cases of febrile morbidity, treated with antibiotics. There was no mortality.

In WHO recommendations for prevention and treatment of postpartum hemorrhage 2012 bulletin suggests that if women do not respond to treatment using uterotonics, or if uterotonics are unavailable, the use of intrauterine balloon tamponade is recommended for the treatment of PPH due to uterine atony. ${ }^{19}$

The limitations of present study include lack of control group with similar blood loss who did not receive balloon tamponade. There was no standard method of estimation of blood loss. Balloon tamponade was not tried in cases of caesarian section. It is recommended to have a larger study with control group and standard methods to estimate the blood loss.

\section{CONCLUSION}

Use of condom catheter is a non-invasive, conservative method of PPH management. Invasive surgical methods like laparotomy and hysterectomy can be avoided. Its use is easy to learn and can be inserted by paramedics and nursing staff quickly till expert help is available. In cases of failure it provides a temporary tamponade effect and time to prepare for other interventions. It can also be used prophylactically in women who are high risk of PPH considering its ease of use and low complication rate. Moreover it's cost effective as it reduces the hospital stay as compared to patients with operative interference. Larger prospective, case-control studies are warranted in relation to the type of balloon used, exact method of PPH quantification, need for further oxytocic and ideal duration of tamponade.

\section{ACKNOWLEDGMENTS}

Authors would like to thank all the consultants, nursing staff and junior residents for maintaining the records and data which helped in the study.

\section{Funding: No funding sources}

Conflict of interest: None declared

Ethical approval: The study was approved by the Institutional Ethics Committee

\section{REFERENCES}

1. World Health Organization. Attending to 136 million births, every year. make every mother and child count. The World Report 2005. World Health Organization, Geneva;2005:62-63.

2. Trends in Maternal Mortality: 1990 to 2010. WHO, UNICEF, UNFPA and The World Bank estimates. Geneva, WHO, 2012. Available at http://whqli bdoc.who.int/publications/2012/9789241503631_eng .pdf

3. AbouZahr C. Antepartum and Postpartum Hemorrhage. In: Murray, L.J. and Boston, A., Eds., Health Dimensions of Sex and Reproduction, Harvard School of Public Health on Behalf of the World Health Organization and the World Bank;1998:165-187.

4. World Health Organization. Reducing the Burden: Postpartum Hemorrhage. 2008. Available at http://www.who.int/maternal_child_adolescent/docu ments/newsletter/mps_newsletter_issue4.pdf

5. Khan KS, Wojdyla D, Say L, Gümezoglu AM, Look PFA. WHO analysis of causes of maternal death: a systematic review. Lancet. 2006;367(9516):1066-74.

6. United Nations. UN Millennium Development Goals. 2015. Available at http://www.un.org/millenniumgoals/

7. World Health Organization, UNICEF, UNFPA, The World Bank. Trends in maternal mortality: 1990 to 2010. WHO, UNICEF, UNFPA and The World Bank estimates. World Health Organization, Geneva, Switzerland;2012:1-69.

8. WHO. Maternal mortality fact sheet, updated November 2016. Available at http://www.who.int/mediacentre/factsheets/fs348/en/

9. Amy JJ. Severe postpartum hemorrhage: a rational approach. Nat Med J India. 1998;11(2):86-88.

10. Registrar, General, India and Centre for Global Health Research, Maternal Mortality in India, 1997 2003: Trends, Causes and Risk Factors, New Delhi: Registrar General, India, 2006:1-40. Available at http://www.cghr.org/wordpress/wp-

content/uploads/RGI-CGHR-Maternal-Mortality-inIndia-1997\%E2\%80\%932003.pdf

11. Goldrath MH. Uterine tamponade for the control of acute uterine bleeding. Am J Obstet Gynecol. 1983;147:869-872.

12. Katesmark M, Brown R, Raju KS. Successful use of a Sengstaken-Blakemore tube to control massive postpartum haemorrhage. $\mathrm{Br} \mathrm{J}$ Obstet Gynecol. 1994;101:259-60

13. Bakri YN, Amri A, Jabbar FA. Tamponade-balloon for obstetrical bleeding. Int $\mathrm{J}$ Gynaecol Obstet 2001;74:139-42.

14. Keriakos R, Mukhopadhyay A. The use of the Rusch balloon for management of severe postpartum haemorrhage. J Obstet Gynecol.2006;26:335-8.

15. Georgiou C. Balloon tamponade in the management of postpartum haemorrhage: a review. Br J Obstet Gynaecol. 2009;116:748-757. 
16. Rathore AM, Gupta S, Manaktala U, Gupta S, Dubey C, Khan M. Uterine tamponade using condom tamponade in non-traumatic postpartum haemorrhage. J Obstet Gynecol Res. 2012;38(9):1162-7.

17. Condous GS, Arulkumaran S, Symonds I, Chapman R, Sinha A, Razvi K. The tamponade test in the management of massive postpartum hemorrhage. Obstet Gynecol. 2003;101:767-72.

18. Seror J, Allouche C, Elhaik, S. (2005) Use of Sengstaken-Blakemore tube in massive postpartum hemorrhage: A series of 17 cases. Acta Obstetricia et Gynecologica Scandinavica. 2005;84:660-4.
19. World Health Organization. WHO Recommendations for the Prevention and Treatment of Postpartum Haemorrhage. World Health Organization, Geneva; 2012.

Cite this article as: Parpillewar MB, Fusey SS. Intrauterine condom catheter tamponade in the management of atonic postpartum haemorrhage: a case series from a tertiary care centre in Central India. Int J Reprod Contracept Obstet Gynecol 2017;6:3468-72. 